\title{
A EVOLUÇÃO DA MULHER NO MERCADO DE TRABALHO
}

\section{ARTIGO ORIGINAL}

OLIVEIRA, Vanessa Ramos da Silva ${ }^{1}$

OLIVEIRA, Vanessa Ramos da Silva. A evolução da mulher no mercado de trabalho. Revista Científica Multidisciplinar Núcleo do Conhecimento. Ano. 06, Ed. 10, Vol. 05, pp. 119-131. Outubro 2021. ISSN: 2448-0959, Link de acesso: https://www.nucleodoconhecimento.com.br/administracao/evolucao-da-mulher, DOI: 10.32749/nucleodoconhecimento.com.br/administracao/evolucao-da-mulher

\section{RESUMO}

A ênfase deste estudo é refletir sobre a evolução e inserção da mulher no mercado de trabalho, bem como as lutas e conquistas destas ao longo dos anos, enfatizando os direitos e desafios encontrados por ela. Neste contexto, tem como questão norteadora: "Como foi a inserção e evolução do gênero feminino no mercado de trabalho?". Tendo como objetivo: analisar a participação da mulher no mercado de trabalho e identificar obstáculos encontrados no mercado de trabalho. Para isto, foi realizada uma pesquisa bibliográfica. Considera-se a relevância do assunto em debate, pois se observa que mesmo a mulher se emancipando profissionalmente, esta ainda vivencia desafios acerca dos papéis ligados a questão de gênero. Por fim, conclui-se que as mudanças nas relações gênero, conquista mais igualitária na dimensão do poder e a quebra sucessiva dos rótulos de gênero que encerram homens e mulheres em normas sociais rígidas, são as conversões necessárias para que as mulheres possam desenvolver seus talentos profissionais e competências.

Palavras-chave: Mulher, Trabalho, Desafios, Direitos.

\footnotetext{
${ }^{1}$ Graduada em Administração, Pós-graduada em gestão de pessoas e planejamento empresarial. ORCID: https://orcid.org/0000-0001-6547-7043

RC: 99290

Disponível em: https://www.nucleodoconhecimento.com.br/administracao/evolucaoda-mulher
} 


\section{INTRODUÇÃO}

O presente trabalho tem como tema "A evolução e inserção da mulher no mercado de trabalho" enfatizando os direitos e desafios encontrados por ela. Nesta perspectiva, tem como questão norteadora: Como foi a inserção e evolução do gênero feminino no mercado de trabalho? Tendo como objetivo: analisar a participação da mulher no mercado de trabalho e identificar obstáculos encontrados pela mulher no mercado de trabalho.

Para alcançar os objetivos propostos utilizou-se como recurso metodológico a pesquisa bibliográfica realizada a partir de análises de materiais disponíveis na internet e publicação literária.

Desde o final do século passado, um mundo globalizado e altamente competitivo começou a exigir novas formas de organização do processo de produção junto com os enormes avanços da tecnologia. Essas mudanças produziram um novo modelo de capitalismo e exigiram uma especialização flexível. Terceirização, trabalho a tempo parcial, contratos informais e outras formas alternativas de acordos tornaramse condições para alguns empregadores continuarem em seus empregos e se manterem competitivos nesta nova situação marcada pelo desligamento. A forma tradicional de trabalho, a crença na estabilidade, altos salários e empregos indefinidos estabelecidos durante o apogeu do capitalismo industrial após a Segunda Guerra Mundial entraram em colapso (WÜNSCH FILHO, 2004)

Essa situação abriu espaço para que as mulheres participassem mais do mercado de trabalho, não só pela necessidade de complementar a renda familiar, mas, também, porque essas mudanças trouxeram mudanças nos padrões de comportamento.

Bruschini e Lombardi (2003) não atribuíram o expressivo aumento da participação feminina nas atividades produtivas apenas às necessidades econômicas ocasionadas pelas mudanças no mundo do trabalho e na sociedade, mas também 
as mudanças na imagem das famílias brasileiras, como por exemplo, a diminuição do número de filhos e o aumento do número de famílias chefiadas por mulheres.

\section{DESENVOLVIMENTO}

Desde o início da Primeira Guerra Mundial, tornou-se evidente a tendência de as mulheres ingressarem no primeiro, segundo e terceiro setores econômicos, ocupando não apenas as áreas rurais, mas também, a indústria e os setores de serviços. Gardey (2003) observou que mesmo exercendo atividades administrativas, a parte feminina não tinha oportunidade de ser promovida, diferentemente dos funcionários do sexo masculino, que desejassem trabalhar neste departamento. Porém, ao longo do século $X X$, as novas tecnologias de comunicação e a mecanização das tarefas levaram a uma revolução administrativa da qual as mulheres fizeram parte e puderam ampliar o seu espaço no setor econômico. Portanto, apenas no século XX, as mulheres passaram a compor a força de trabalho global, sendo incialmente sua participação no mercado comparável à dos homens (CORRÊA, 2004).

O Mercado de Trabalho após a década de 90 passou por diversas mudanças através de projetos de reestruturação produtiva. Houve melhora na flexibilidade dos contratos de trabalho, várias transformações que aumentaram positivamente o crescimento nos setores dos serviços, trabalho informal e por conta própria (MARTINS; OLIVEIRA, 2017).

No Brasil, as relações trabalho-gestão, têm características próprias e não devem ser subestimadas, pois, promoveram a produtividade setorial e regional, além de gerar condições de trabalho instáveis para parte da população da época, devido a passagem incompleta da sociedade agrícola para a sociedade industrial urbana, o que acarretou especificidades das mudanças ocorridas na reorganização produtiva das relações de trabalho no nosso país. 
No início do século XXI houve grandes avanços no Mercado de Trabalho, a formalização garantiu o acesso do trabalhador aos Direitos Trabalhista, sociais e Previdenciários, e, com isso, obteve-se um crescimento da renda real do trabalho, juntamente com a redução das desigualdades pessoais de rendimentos (MATTOS, 2015).

Podemos citar também o papel da mulher no mercado de trabalho no Brasil. Estudos relatam que a partir da década de 70 , se intensificaram o trabalho das mulheres no meio dos pioneiros, onde existia grandes diferenças salariais e elevada concentração destas nos setores que eram ligados ao comércio, a serviços, a trabalhos domésticos, em cargos vulneráveis e de baixa exigência de qualificação profissional. Essas características foram as que destacaram na trajetória da inserção das mulheres no mercado de trabalho, ou seja, desde o princípio existe desigualdade na divisão sexual do trabalho e na atribuição das mulheres. (INSTITUTO DE ECONOMIA, 2017).

Antes da inserção da mulher no mercado de trabalho, elas eram vistas apenas para realizar afazeres domésticos e cuidar da criação dos filhos. Porém, após a I (1914 1918) e a II (1939 - 1945) guerras mundiais, onde os homens foram as frentes de batalhas, as mulheres, passaram a assumir o lugar dos maridos no mercado de trabalho. Após o fim das Guerras, muitos homens foram mortos e alguns ficaram incapacitados, assim, as mulheres continuaram trabalhando, desta forma, as mulheres, passaram a ser introduzida no mercado de trabalho (MUNIZ; BACHA; PINTO, 2015).

A Revolução Industrial foi um grande marco para trajetória das mães nas fábricas, sendo muito procuradas pelos empresários, pois aceitavam salários inferiores aos dos homens pelo mesmo serviço realizado. Mesmo com toda a discriminação do mercado de trabalho, todos os problemas enfrentados como a desigualdade salarial e o valor da mesma no ambiente de trabalho, a mulher, passou a deixar a maternidade e projetos pessoais, para crescer profissionalmente (MUNIZ; BACHA; PINTO, 2015). 
[...] sustento de uma família [...] no século XXI têm sofrido mutações diárias e cada vez mais frequentes e constantes. As famílias de média e baixa renda têm a necessidade de ter tanto o homem quanto a mulher no mercado de trabalho para aumentar a renda familiar, que mesmo assim, em vários casos não é suficiente. De outro lado, temos a necessidade da afirmação das mulheres perante a sociedade, e por isso, hoje no Brasil temos $44,5 \%$ dos postos de trabalho das melhores empresas, conforme relata o Jornal Diário Popular, no artigo datado de 07 de março de 2009 de autor não informado [...] (BAYLÃO; SCHETTINO, 2014, p. 02).

A despeito disto, Paoli (1985) observou que, além de descrever as mulheres como vulneráveis e inferiores, os regulamentos do Ministério do Trabalho de 1932 sobre o trabalho feminino também restringiam as escolhas dos empregadores para 0 trabalho feminino e fortaleciam o papel das mulheres nas funções familiares. regulamento estipulava que as mulheres trabalhassem em turnos noturnos, em locais insalubres, proporcionem locais de trabalho higiênicos, usassem cadeiras para que o trabalho não fosse muito cansativo. Trazia como direitos a garantia da gestante de não trabalhar por dois a três meses, proporcionava a elas intervalos para amamentar e onde isto deveria ocorrer na fábrica. Embora os empregadores concordem com esses direitos verbalmente, estes eram violados na prática.

Na década de 30, o presidente Getúlio Vargas criou as Leis trabalhistas, pois até então todos os trabalhadores, incluindo as mulheres, trabalhavam de forma desumana, com jornadas sem limite, em ambientes sujos, insalubres e úmidos. A implantação da legislação trabalhista mudou as condições de trabalho das mulheres, pois elas eram mais exploradas devido a sua condição aparente "fragilizada" quando comparada ao homem (FRANCISCANI, 2010).

De acordo com Santos (2016) com o decorrer dos anos a integração da mulher no mercado de trabalho aumentou consideravelmente, desta forma, surgiram leis para que este trabalho fosse regulamentado e deixasse de ser desfavorecido beneficiando as mulheres. De acordo com Probst (2003, p. 2) "[...] estabelecido na Constituição de 32 que sem distinção de sexo, a todo trabalho de igual valor correspondente salário igual; [...]". A inclusão das mulheres no mercado de trabalho 
tanto formal quanto informal se expandiu, chegando a mais de $40 \%$ da força de trabalho em vários países evoluídos. (SANTOS; ALVES, 2016).

Em 1988 foi promulgado a Carta Magna que estabeleceu a igualdade de gênero no âmbito de trabalho, sendo, por meio deste, aplicado a proteção dos direitos das mulheres nos artigos $3^{\circ}$, IV e 5ํㅡ, I, deste dispositivo legal. Através da Constituição Cidadã, foi observado que o trabalho deve ser compreendido como um direito social, conforme demonstrado no artigo $6^{\circ}$ "são direitos sociais a educação, a saúde, a alimentação, o trabalho, a moradia, o transporte, o lazer, a segurança, a previdência social, a proteção à maternidade e à infância, a assistência aos desamparados, na forma desta Constituição". Após toda batalha para se ganhar o direito no mercado de trabalho, 0 artigo $7^{\circ}$ da Constituição Federal, assegurou a licença maternidade: "Art. $7^{\circ}$ São direitos dos trabalhadores urbanos e rurais, além de outros que visem à melhoria de sua condição social: XVIII - licença à gestante, sem prejuízo do emprego e do salário, com a duração de centro e vinte dias". Essas Leis serviram para acabar com a discriminação de gênero no âmbito do trabalho visando a necessidades da mulher tanto biológica como psicológica (SIQUEIRA; SAMPARO, 2017).

A história da evolução dos direitos femininos se iniciou durante o século XVIII/XIX após o crescimento industrial, proporcionando a mulher o direito do trabalho, mesmo assumindo funções que eram realizadas por homens. A despeito dos poucos benefícios adquiridos, as mulheres, continuavam em desvantagens, pois estavam sempre sujeitas as longas horas de trabalho e sem leis para protegê-las, trabalhando em condições desfavoráveis, recebendo salários baixos para não perderem seus empregos (SANTOS; ALVES, 2016).

No Brasil, o primeiro grupo de mulheres feministas surgiu em 1972, em São Paulo, lutando através de vários movimentos para garantir as mulheres direitos. Através desses movimentos houve várias conquistas relacionadas as mulheres no mercado de trabalho, como por exemplo, a redução nas jornadas de trabalho, o direito a 
receber salário mesmo estando em licença maternidade, a igualdade no salário, o direito ao voto, entre outros (ALVES; ALVES, 2013).

Desde o início, houve muitos obstáculos, devido à fragilidade feminina quando comparada ao homem, para a inserção das mulheres no mercado de trabalho. Mesmo com todas as dificuldades, as mulheres, permaneceram firmes na decisão de se destacarem dentro de seu trabalho. Podemos destacar, dentre os obstáculos encontrados, o machismo e o preconceito, dificultando, assim, a mulher, a adquirir "poder" nas empresas, podendo, também, ser compreendido por alguns homens ficarem constrangidos quando há uma mulher na liderança (SILVA, 2017).

Um grande obstáculo encontrado pela mulher na inserção no mercado de trabalho, além da discriminação, é a desigualdade salarial entre homens e mulheres. Antes havia a ideia de que não existia necessidade de a mulher ganhar salário equivalente ou superior ao do homem, pois o sustento da casa era do homem e não da mulher, mas com o decorrer dos anos, essa realidade mudou e muitas mulheres passaram a levar o sustento para dentro de suas casas, e, dessa forma, a conquistar espaço dentro do mercado de trabalho, havendo um aumento no seu rendimento quando comparado com os homens (SOUZA; SANTOS, 2014).

Quando falado sobre desafio profissional, para o homem, é algo de mais fácil acesso, tendo maior foco em seu futuro, entretanto, para as mulheres, há grandes desafios devido à dupla jornada, sendo a profissional e a familiar, tendo que lidar com o trabalho durante o dia e o cuidado do lar nos momentos de folgas. Dessa forma, as mulheres, para terem uma grande evolução no universo profissional, não sendo mais vistas apenas como talentos de segunda categoria, mas sendo analisadas de outra forma, quando vista de uma maneira mais profissional (SILVA; BERRÁ, 2018).

Um dos grandes desafios da mulher sobre sua profissão é a sua vida pessoal, uma vez que os sentimentos envolvidos acabam influenciando em sua carreira, pois o sentimento de culpa por não dar a atenção necessária aos filhos influência muito na 
relação do trabalho e família, o que acaba interferindo em sua dedicação e/ou determinação em alcançar seus objetivos profissionais (SILVEIRA; FLECK, 2019).

Com o aumento da ocupação da mulher em vários cargos no mercado de trabalho, verificou-se um aumento na desigualdade de gênero, onde era nítido a diferença de salário entre homens e mulheres em cargos do mesmo nível. De acordo com Proni (2017) "a desigualdade de gênero se expressa no salário médio contratual.", ou seja, a discriminação se inicia no momento da contratação onde há diferenças de salários por sexo. Temos que destacar, também, que a maior desigualdade de remuneração entre homens e mulheres se dá através de contratações com nível superior de educação (PRONI; PRONI, 2017).

A introdução da mulher no mercado de trabalho seja por motivos financeiros, por padrões culturais, ou pela realização pessoal, acarretou o aumento da discriminação dela, a desigualdade profissional entre homens e mulheres se tornaram nítidas. Estudos comprovam que o setor feminino recebe salários menores quando comparados a cargos iguais com a mesma escolaridade entre homens e mulheres (PEREIRA; SANTOS; BORGES, 2005).

Por outro lado, a intensa afluência das mulheres ao mercado de trabalho não foi acompanhada por uma diminuição significativa das desigualdades profissionais entre homens e mulheres. A maior parte dos empregos femininos continua concentrada em alguns setores de atividades e agrupada em um pequeno número de profissões, e essa segmentação continua estando na base das desigualdades existentes entre homens e mulheres no mercado de trabalho, incluindo as salariais (ABRAMO, 2000, p. 78).

Após tantas lutas e batalhas para a atuação da mulher no mercado de trabalho, com o tempo, as mulheres, começaram a se tornarem líderes, apesar de toda dificuldade. As empresas passaram a ter visão sobre as competências das mulheres, mesmo com desconfiança da liderança feminina, visando mostrar que tem capacidade profissional, perfil e poderem até ser melhores quando comparado a profissionais masculinos (CUNHA; SPANHOL, 2014). 
Deve-se ressaltar que as mulheres, com sua persistência para crescer no âmbito de trabalho, através do aumento da escolaridade e aperfeiçoamento em cursos, proporcionou-Ihes as competências necessárias para concorrerem com os homens a vários cargos, inclusive os de liderança, "[...]a participação da mulher no contexto do trabalho e os reflexos da sua maneira de pensar, agir e sentir sobre os fenômenos evidenciados na complexidade atingem uma dimensão bem maior do que se imagina" (CUNHA; SPANHOL, 2014).

Para Ceola (2014) um bom líder tem como qualidade motivar as pessoas a segui-las e destina essa característica as mulheres, isto é, incentivar a capacidade das mulheres de motivar é um grande diferencial para o papel do líder na atualidade. Podemos também destacar algumas qualidades de líderes que estão presentes na liderança feminina, como: alta inteligência emocional; a capacidade de motivar e inspirar o próximo; dispõe para assumir riscos; visão clara dos objetivos desejados; capacidade na formação de equipe e auxiliar os mesmos; de influência; de estratégia e diplomacia. Podemos observar que as mulheres influenciam em seu meio de trabalho com qualidade e capacitação atuando como líderes (CEOLA 2014).

A mulher brasileira no mercado de trabalho através de movimentos feministas conquistara seu espaço na economia nacional representando uma boa porcentagem na força de trabalho. Sua força aumentou de forma significativa, tornando-se chefe da sua própria vida, além dos cuidados da casa como mãe, esposa e dona de casa, passou a deixar de ser apenas uma parte da família, mas um significativo papel no sustento do lar, através do seu ingresso no mercado de trabalho, lento, porém muito sólido (BAYLÃO; SCHETTINO, 2014).

Deve-se sempre relembrar que nas décadas anteriores os movimentos feministas abordavam a aprovação do meio feminino no meio do mercado de trabalho, esforçando pela igualdade entre homens e mulheres, pela igualdade do exercício profissional, sem distinção devido à maternidade e sem preconceito devido ao papel que a mulher exerce na família (CADERNO DE SAÚDE PÚBLICA, 2018). 
Apesar de todos os obstáculos, as mulheres conquistaram o mercado de trabalho alcançando cargos de liderança, obtendo sua independência financeira, tendo participação na economia e no meio social, dessa forma, influenciando sua autoestima e autorrealização, mostrando a capacidade de liderar e administrar com versatilidade, persuasão e quebrando paradigma (SILVA; CARVALHO; SILVA, 2017).

[...] a mulher executiva é reconhecida por sua capacidade técnica e gerencial; porém, a mulher sempre vence seus obstáculos profissionais conciliando-o com sua trajetória familiar: casa, esposo e filhos. [...] buscam a valorização e a igualdade dos direitos com os homens, no mercado de trabalho. As mulheres também se destacam no setor cooperativista, como integrantes de famílias de associados, recebendo informações que podem ser úteis no gerenciamento dos negócios familiares (SILVA; CARVALHO; SILVA, 2017, p 7).

Para Seggiaro (2017) ainda existe discriminação e influência no ambiente de trabalho, com a discriminação de gêneros, o assédio pela vestimenta, os padrões de beleza exigida e a falta de hierarquia por parte do homem quando a mulher se encontra na liderança. A maternidade também influencia nas disputas por vagas. $O$ tratamento dentro do local de trabalho difere entre homem e mulher, as contratações com mulheres são menores.

Como toda conquista tem seu lado bom, existe o lado ruim, e, uma delas, que surgiu com o aumento a responsabilidade da mulher no mercado de trabalho, foi o prejuízo na relação trabalho e a maternidade, tendo que haver novos arranjos no ambiente familiar, acarretando a diminuição do tempo entre mãe e filho, obrigando a mesma a utilizar de outros meios, como a babá, a família, as escolas com tempo integral e as creches (ROCHA; BURD, 2016).

Bittencourt (1980) destaca dois aspectos fundamentais da participação das mulheres no mercado de trabalho: de um lado, o fato de as mudanças induzidas pelo capitalismo possibilitarem uma maior participação das mulheres, o que é considerado uma salvação. O meio ambiente e a capacidade dos homens de participar da produção social permitiram que escapassem; por outro lado, o fato de 
colocá-lo no contexto da produção não significa que ele se exime dos deveres familiares, nem de sua emancipação e emancipação, porque continua a viver em condições de exploração, agora não só em família, mas profissional também.

A conquista na realização profissional da mulher está diretamente ligada à sua subsistência e a de sua família, visto que sua renda é utilizada para as despesas do seu lar. Quando a mulher se dedica ao trabalho acaba deixando a família um pouco de lado, pois quando tenta dividir seu tempo entre trabalho e família ocorre uma sobrecarga sobre a mesma, onde administrar os dois ambientes se torna complicado (ROCHA; BURD, 2016).

É importante que haja equilíbrio entre trabalho e a vida privada, buscando preservar a saúde física e mental da mulher, possibilitando a ela desfrutar de momentos prazerosos, visando à saúde como um direito fundamental, incluindo o lazer, assegurando o seu desenvolvimento biopsicossocial. [...] As mulheres com filhos sentem-se mais estressadas porque têm que dividir o seu tempo com o filho, sofrendo frequentes interrupções no lazer. Elas se utilizam da estratégia multitarefa, desempenhando várias funções ao mesmo tempo, porém não experimentam plenamente o momento em que estão vivendo. (ROCHA; BURD, 2016, p. 16).

A mulher, além dos obstáculos encontrados no âmbito de trabalho, vivencia também as dificuldades em administrar seu lar, tendo menos tempos para atividades domésticas, para a maternidade, ou seja, dedicação aos filhos. Esses fatores geram um desequilíbrio, onde a mulher tem que escolher em qual se dedicar. Em alguns casos, as mulheres, se veem na necessidade de reduzir a carga horária para se ter mais tempo para o parceiro, seus filhos e os afazeres domésticos (ROCHA; BURD, 2016).

\section{CONSIDERAÇÕES FINAIS}

Diante do exposto, através de uma revisão bibliográfica de caráter qualitativo, referente a evolução e inserção da mulher no mercado de trabalho, observa-se que as circunstâncias em relação à introdução mulher no mercado trabalho são complexas, algumas imposições estiveram presentes, como a necessidade consistente qualificação e a responsabilidade conforme as funções domésticas. A

RC: 99290

Disponível em: https://www.nucleodoconhecimento.com.br/administracao/evolucaoda-mulher 
conquista de novos papeis, a oportunidade de execução profissional, não fez expirar as tradicionais atividades sociais atribuídas à mulher. O que se nota é um arsenal de tarefas profissionais e domésticas que podem corromper a saúde física e emocional das mulheres. Constantemente elas sentem que não estão executando bem os papeis esfera doméstica nem progredindo de forma pertinente o lado profissional. Por outro lado, o trabalho pode ser fonte prazer e reconhecimento social.

\section{REFERÊNCIAS}

ABRAMO, L. A situação da mulher latino-americana. 0 mercado de trabalho no contexto da reestruturação. Mulher e trabalho experiência de ação afirmativa. S.P.: Boitempo Editorial, 2000.

ALVES, A. C. F.; ALVES, A. K. S. As trajetórias e lutas do movimento feminista no Brasil e o protagonismo social das mulheres. IV seminários CETROS, Neodesenvolvimentismo, trabalho e questão social. Fortaleza - CE, p. $113-121$, 2013.

BAYLÃO, A. L. S.; SCHETTINO, E. M. O. A inserção da mulher no mercado de trabalho brasileiro. XI Simpósio de Excelência em Gestão e Tecnologia, Rio de Janeiro, 2014.

BITTENCOURT, S. R. V. A participação da mulher no mercado de trabalho e o cuidado dispensado aos filhos menores de sete anos, durante a ausência materna. 1980. 75f. Dissertação (Mestrado em Saúde Comunitária) - Universidade Federal da Bahia, Salvador, 1980.

BRUSCHINI, C.; LOMBARDI, M. R. Mulheres e homens no mercado de trabalho brasileiro: um retrato dos anos 1990. In: MARUANI, M. e HIRATA, H. (Orgs.). As novas fronteiras da desigualdade: homens e mulheres no mercado de trabalho. São Paulo: Senac, 2003. 
CADERNO DE SAÚDE PÚBLICA. A história do trabalho das mulheres no Brasil: perspectiva feminina. Os direitos das mulheres: feminismo e trabalho no Brasil (1917 - 1937). FRACCARO, G. Associação Brasileira de Estudos do trabalho/Editora FGV. Rio de Janeiro, 2018.

CEOLA, M. Liderança feminina na realidade social brasileira. FEMA - Fundação educacional do município de Assis, Assis - SP, 2014.

CORRÊA, A. M. H. O assédio moral na trajetória profissional de mulheres gerentes: evidências nas histórias de vida. 2004. 184f. Dissertação (Mestrado em Administração) -Centro de Pós-Graduação e Pesquisa em Administração da Universidade Federal de Minas Gerais, Belo Horizonte, 2004.

CUNHA, A. C. C.; SPANHOL, C. I. D. Liderança Feminina: características e importância à identidade da mulher. Revista Saber Humano, ano 4, № 5, p. 91 114, 2014

FRANCISCANI, J. S. A mulher no mercado de trabalho e a luta pela valorização. Instituto Municipal de Ensino Superior de Assis - IMESA, Assis - SP, 2010.

GARDEY, D. Perspectivas históricas. In: MARUANI, M. e HIRATA, H. (Orgs.). As novas fronteiras da desigualdade: homens e mulheres no mercado de trabalho. São Paulo: Senac, 2003.

INSTITUTO DA ECONOMIA. Mulheres: mundo do trabalho e autonomia econômica. Caderno 3: as mulheres e o mercado de trabalho. Instituto da Economia - UNICAMP, São Paulo, 2017.

MARTINS, B. V.; OLIVEIRA, S. R. Qualificação profissional, mercado de trabalho e mobilidade social. Cursos superiores de tecnologia. Sociedade, contabilidade, Rio de Janeiro, v. 12, № 2, 2017. 
MATTOS, F. A. M. Avanços e dificuldades para o mercado de trabalho. Estudos avançados, Rio de Janeiro, p. 69-85, 2015.

MUNIZ, D. D.; BACHA, F. B.; PINTO, J. M. Participação feminina no mercado de trabalho. Revista Científica Eletrônica UNISEB, Ribeirão Preto - SP, v. 6, № 6, p. 82 $-97,2015$.

PAOLI, M. C. Os trabalhadores urbanos na fala dos ouros. In: LOPES (org.) Cultura e identidade operária. Rio de Janeiro: Marco Zero, 1985.

PEREIRA, R. S.; SANTOS, D. A.; BORGES, W. A mulher no mercado de trabalho. II jornada Internacional de Políticas Públicas, São Luiz - MA, 2005.

PRONI, T. T. R. W.; PRONI, M. W. Discriminação de gênero em grandes empresas no Brasil. Revista Estudo Feministas, Florianópolis - SC, v. 26, no 141780, 2017.

PROSBT, R. E. A evolução da mulher no mercado de trabalho. Gestão estratégia de recursos humanos, Instituto Catarinense de pós-graduação - ICPG, p. 2, 2003.

ROCHA, R. R. F.; BURD, A. C. S. J. A luta da mulher universitária na contemporaneidade: conciliando família, trabalho e realização pessoal. Faculdade Ciências da Vida - FGV, Sete Lagoas - MG, 2016.

SANTOS, B. M.; ALVES, J. S. A evolução da mulher no mercado de trabalho: comparação entre ontem e hoje. FABE em revista, Bertioga - SP, v. 6, o 8, 2016.

SEGGIARO, F. B. Mulheres no mercado de trabalho: análise das dificuldades de gêneros enfrentadas pelas mulheres do século XXI. Revista Metodista de Administração do Sul, v. 2, nº 1, 2017.

SILVA, C. R. R.; CARVALHO, P. M.; SILVA, E. L. Liderança feminina: a imagem da mulher atual no mercado corporativo das organizações brasileiras. 
Educação, Gestão e Sociedade: Revista da Faculdade Eça de Queirós, ano 7, № 25, 2017.

SILVA, F. B. Desafios das mulheres em cargos de liderança. Lajeados - RS, 2017.

SILVA, F. B.; BERRÁ, L. Desafios das mulheres em cargos de liderança. Revista destaque acadêmico, Lajeado - RS, v. 10, № 1, p. 166 - 185, 2018.

SILVEIRA, J. C.; FLECK, C. F. Forte como... uma mulher: uma análise dos desafios enfrentados pelas mulheres no mercado de trabalho. Unipampa Universidade Federal do Pampa, Bagé - RS. Disponível em <http://dspace.unipampa.edu.br/bitstream/riu/2097/1/Josianne\%20Correa\%20Silveir a.pdf>, acesso em 20 de novembro de 2019.

SIQUEIRA, D. P.; SAMPARO, A J. Os direitos da mulher no mercado de trabalho: da discriminação de gênero à luta pela igualdade. Revista Direito em debate, ljuí - RS, Ano XXVI, no 48, p. 287 - 325, 2017.

SOUZA, E. S.; SANTOS, S. P. Mulheres no mercado de trabalho: um estudo com estudantes universitários do curso de administração de uma faculdade particular de São Paulo (SP). Revista Eletrônica dos discentes da Faculdade Eça de Queirós, ano 3, no 3, 2014.

Enviado: Junho, 2021.

Aprovado: Outubro, 2021. 